\title{
AN EFFICIENT PROCEDURE FOR THE PRODUCTION OF FATTY ACID HYDROPEROXIDES FROM HYDROLYZED FLAX SEED OIL AND SOYBEAN LIPOXYGENASE.
}

\author{
M.-L. Fauconnier * and M. Marlier \\ U.E.R. de Chimie Générale et Organique \\ Faculté Universitaire des Sciences Agronomiques \\ 2, Passage des déportés B-5030 Gembloux Belgium
}

\begin{abstract}
Summary
Production of 13-linolenic acid hydroperoxides from hydrolyzed flax seed oil using lipoxygenase extracted from soybean seeds.has been achieved with high transformation yields ( $60 \mathrm{~g} \cdot \mathrm{l}^{-1} \cdot \mathrm{h}^{-1}$ ) with a high purity ( $94 \%$ of 13 -isomers) in a 10 liter reactor without addition of any solvent or surfactant. The reaction limiting factor is, probably, the accessibility of the substrate to the enzyme.
\end{abstract}

\section{Introduction}

Lipoxygenase (E.C. : 1.13.11.12) is an intramolecular dioxygenase which catalyses the hydroperoxidation of polyunsaturated fatty acids containing a $1 \mathrm{Z}, 4 \mathrm{Z}$ pentadiene structure (linoleic or linolenic acid). It leads to the production of conjugated hydroperoxides which can be further degraded into volatile aldehydes by hydroperoxide lyases. Depending on the origin of the enzyme and on the reaction conditions, variable amounts of 9- and 13-hydroperoxides are formed. Linolenic acid 13-hydroperoxide (13-Ln $\mathrm{OOH})$ leads to the formation of high value 'green note' aromatic compounds cis-3-hexenol and trans-2-hexenal, so called leaf alcohol and leaf aldehyde (Figure 1). Those molecules are used by flavorists in the composition of aromas destinated to the food industry (Fauconnier and Marlier, 1996; Hatanaka, 1993; Hildebrand, 1989). Soybean seed is one of the richest source of lipoxygenase. The enzyme is mainly composed of three isoenzymes; isoenzyme-1 (Lox-1) can be easily distinguished from isoenzyme-2 (Lox-2) and 3 (Lox-3) on their pH optimum values (respectivelly 9.5 and 6.5). Lox-1 produces large amounts of 13-hydroperoxides while Lox-2 and Lox-3 gives equal amounts of the 9 and 13 isomers. At low temperature $\left(2{ }^{\circ} \mathrm{C}\right)$, Lox-1 is the only isoenzyme still working. (Chism, 1985; Axelrod, 1981; Leu, 1974). Different authors have reported on the production of hydroperoxides by lipoxygenases: Iacazio et al. (1990) used commercial soybean lipoxygenase to produce 13-hydroperoxides of linoleic acid in a 2 liters vial under $\mathrm{O}_{2}$ pressure. They obtained $80 \%$ of transformation $\left(22 \mathrm{~g} . \mathrm{I}^{-1} \cdot \mathrm{h}^{-1}\right.$ ) in one hour with a high degree of purity ( $96 \%$ of 13-isomer). Piazza et al.(1994) synthetized various hydroperoxides with immobilized lipoxygenase in a biphasic system water/octane (8/1). The purity of the reaction products was also high but the amount of substrate transformed was low $\left(0.25 \mathrm{~g} \cdot \mathrm{I}^{-1} \cdot \mathrm{h}^{-1}\right)$. Drouet et al.(1994) 
used the same biphasic system but obtained higher yields of transformation $\left(12 \mathrm{~g} \cdot \mathrm{I}^{-1} \cdot \mathrm{h}^{-1}\right)$. We report herein on the efficient production of 13-hydroperoxides of linolenic acid in a 10 liter reactor without addition of any surfactant or solvent and using cheap ingredients : hydrolyzed flax seed oil and lipoxygenase extracted from soybean seeds.

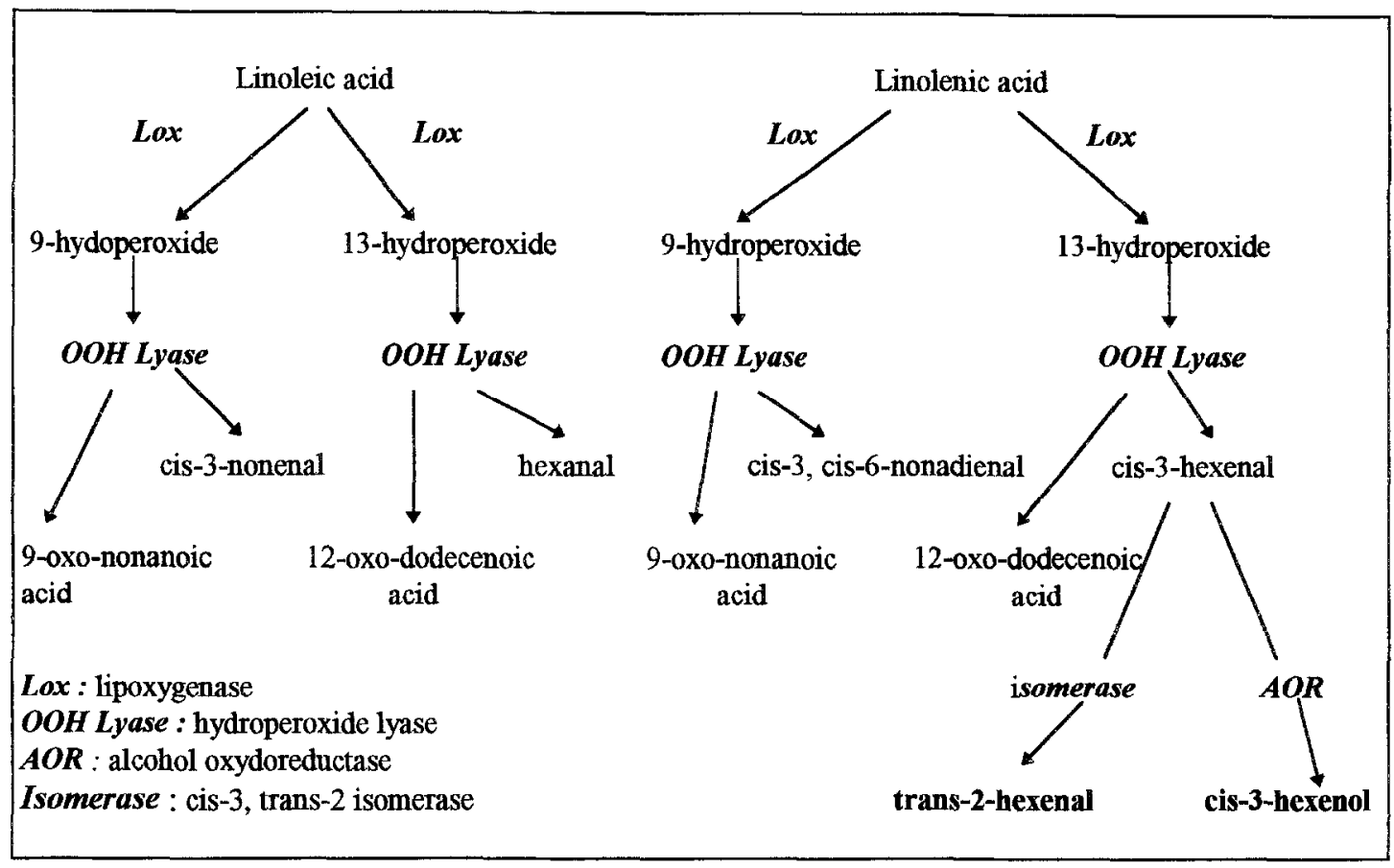

Figure 1 : Enzymatic degradation of polyunsaturated fatty acids

\section{Material and Methods}

Enzyme extraction : $1 \mathrm{~kg}$ of ground soybean seeds (variety Kador from Rustica, Toulouse) were extracted by 6 liters of $0.2 \mathrm{M}$ sodium acetate buffer $\mathrm{pH} 4.5$ for one hour. The extract was filtered through cheesecloths and submitted to fractionated precipitation with ammonium sulfate. The extract was brought to $40 \%$ of saturation agitated 1 hour and centrifuged ( 8000 $\mathrm{g}, 10 \mathrm{~min}$.). The supernatant was brought to $60 \%$ of saturation, agitated one hour and centrifuged $(8000 \mathrm{~g}, 10 \mathrm{~min}$.). The residue was dissolved in $250 \mathrm{ml}$ of $0.2 \mathrm{M} \mathrm{pH} 9.5$ borate buffer and directly lyophilized. The determination of enzyme activity was realized by the method of Surrey (1964) and the protein content was measured according to the Lowry method. One unit of activity is defined as the amount of enzyme which generates an increase of absorbance of 0.001 in one minute at $234 \mathrm{~nm}$ at $\mathrm{pH} 9.0$ and $20^{\circ} \mathrm{C}$ when linoleic acid is used as substrate. One kilo of soybean seeds treated as described above furnishes $100 \mathrm{~g}$ dried powder with a specific activity of 300,000 units per mg of protein and a total activity content of $5 \times 10^{8}$ units.

Flax seed oil hydrolysis : the oil was dissolved in methanol $(\mathrm{v} / \mathrm{v})$, warmed at $70^{\circ} \mathrm{C}$ and hydrolyzed by $\mathrm{NaOH} 12 \mathrm{M}$ for 30 minutes under reflux. The fatty acids were neutralized with $\mathrm{H}_{2} \mathrm{SO}_{4} 2 \mathrm{M}$ and washed three times with hot water. Analysis of the fatty acids was realized by GLC according to Lognay et al. (1988) and revealed $55 \%$ of linolenic acid, $14 \%$ of linoleic acid, $18 \%$ of stearic acid and $5 \%$ of palmitic acid.

Positional and geometrical analysis of the hydroperoxides produced were realized by HPLC on a Si column according to Sanz et al. (1993). 
Kinetic of the reaction : the evolution of the reaction was monitored by diluting a small amount of the reaction medium in methanol and by measuring the absorbance at $234 \mathrm{~nm}$ against a blanck.

Laboratory scale production : reactions were performed in $50 \mathrm{ml}$ vials with $20 \mathrm{ml}$ of medium $\left(0.2 \mathrm{M} \mathrm{pH} 9.5\right.$ borate buffer) under a constant flow of $\mathrm{O}_{2}$ in an ice bath at $2{ }^{\circ} \mathrm{C}$. The reaction medium was maintained at saturation of $\mathrm{O}_{2}$ during all the reaction (controlled by an oxymeter). All the experiments were performed in triplicate and a blanck was always realized. The first trials were made with pure linolenic acid (Sigma, L 2376). Hydrolyzed flax seed oil obtained as described above was used as a cheap source of linolenic acid in a second time.

Reactor scale production : reactions were performed in a 20 liters Biolaffite reactor filled up with 10 liters of reaction medium (see after). The agitation was ensured by a disk-mounted blade turbine (TD4) of $0.1 \mathrm{~m}$ of diameter. The reaction parameters were: $2^{\circ} \mathrm{C}, 400$ or $800 \mathrm{rpm}$, pH 9.5, oxygen content maintained at saturation. The appropriate amount of hydrolyzed flax seed oil was suspended in 9.5 liters of $0.2 \mathrm{M} \mathrm{pH} 9.5$ borate buffer and homogenized using a microfluidizer (Microfluidizer M $110 \mathrm{~T}$ from Microfluidics corporation) with a output pressure of $50,000 \mathrm{KPa}$. The enzyme was solubilized in 0.5 liter of the same borate buffer.

\section{Results and discussion}

Laboratory scale productions were undertaken to determine optimum reaction parameters. The first parameter studied was the production of hydroperoxides as a function of time for different substrate concentrations. 5000 units of lipoxygenase was used in $20 \mathrm{ml}$ of reaction medium and the concentration in pure linolenic acid was gradually increased from $5 \times \mu \mathrm{mol} / 1$ to $3.7 \mathrm{mmol} / 1$ (Figure 2).
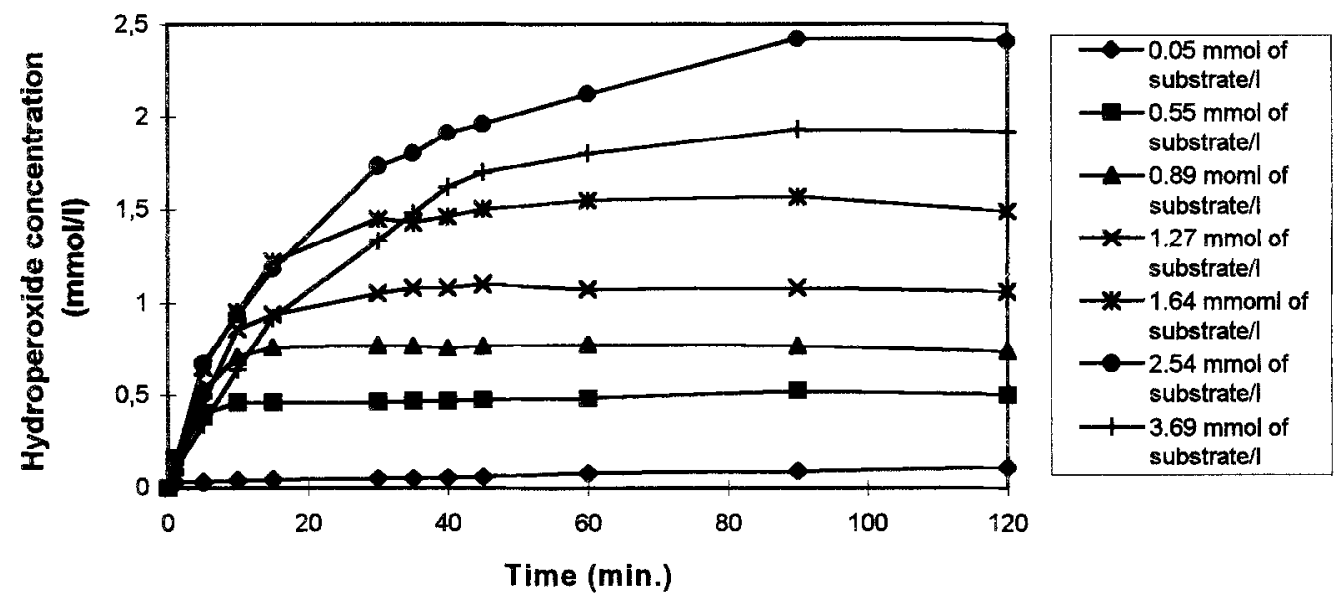

Figure 2 : Hydroperoxide production as a function of time for different substrate concentrations ( 5.000 units of lipoxygenase in $20 \mathrm{ml}$ of reaction medium).

Almost all the substrate was transformed in one hour for concentrations up to $2.5 \mathrm{mmol} / \mathrm{l}$ but for higher concentrations, the transformation yields rapidly decreased (Table 1). This last result was considered as the optimal enzyme/substrate ratio. In additional experiments, the optimal ratio enzyme/substrate was maintained constant and all the quantities were multiplied by 2,3 , $4,4.5$ and 5 . Substrate concentration up to $10.1 \mathrm{mmol} / 1$ could be oxygenated with a good transformation yield using 1 millon of activity units in $20 \mathrm{ml}$ of reaction medium (Table 1 ). 
For higher substrate concentrations, the transformation yields began to decrease and attempts to increase it by modifying the enzyme and/or substrate concentration were unsuccessful. When pure linolenic acid was replaced by hydrolyzed flax seed oil in concentrations such as the linolenic acid content was similar, the results obtained were comparable. For all laboratory scale productions, the proportion of 13- and 9-hydroperoxides was determined. In all cases, the ratio of 13/9-hydroperoxides was better than $95 / 5$. It is logical since the reaction conditions used $\left(2^{\circ} \mathrm{C}, \mathrm{pH} 9.5\right)$ are particularly suitable for Lox-1. In the cases where hydrolyzed flax seed oil was used as substrate, 13-hydroperoxides from linoleic acid were formed because this fatty acid is also substrate for soybean lipoxygenase.

\begin{tabular}{|c|c|c|c|c|c|c|}
\hline $\begin{array}{c}\text { Substrate } \\
\text { concentration } \\
(\mathrm{mmol} / \mathrm{l})\end{array}$ & $\begin{array}{c}\text { Enzyme } \\
\text { concentration } \\
\text { (units/l) }\end{array}$ & $\begin{array}{c}\text { Transfor- } \\
\text {-mation } \\
\text { yields }\end{array}$ & $\begin{array}{c}\text { Substrate } \\
\text { concentration } \\
(\mathrm{mmol} / \mathrm{l})\end{array}$ & $\begin{array}{c}\text { Enzyme } \\
\text { concentration } \\
\text { (units/l) }\end{array}$ & $\begin{array}{l}\text { Transfor- } \\
\text {-mation } \\
\text { yields }\end{array}$ & $\begin{array}{l}\text { Multipli- } \\
\text {-cating } \\
\text { factor }\end{array}$ \\
\hline 0.05 & 250,000 & $99 \%$ & \begin{tabular}{|l}
5.07 \\
\end{tabular} & 500,000 & $93 \%$ & 2 \\
\hline 0.55 & 250,000 & $96 \%$ & 7.61 & 750,000 & $89 \%$ & 3 \\
\hline 0.89 & 250,000 & $95 \%$ & 10.15 & $1,000,000$ & $88 \%$ & 4 \\
\hline 1.27 & 250,000 & $95 \%$ & 11.42 & $1,125,000$ & $81 \%$ & 4.5 \\
\hline 1.64 & 250,000 & $95 \%$ & 12.68 & $1,250,000$ & $73 \%$ & 5 \\
\hline 2.54 & 250,000 & $95 \%$ & & & & \\
\hline 3.69 & 250,000 & $52 \%$ & & & & \\
\hline
\end{tabular}

Table 1 : Transformation yields for different linolenic acid and enzyme concentrations

When the reaction was carried out in a 10 liter reactor, higher concentrations in hydroperoxides were obtained, especially when the agitation rate was increased from 400 to $800 \mathrm{rpm}$.

For substrate concentrations higher than $10 \mathrm{~g} / \mathrm{l}$, a problem of solubilization occurred because of the tendancy of the fatty acid to aggregate. The problem was solved by using a microfluidizer to homogenize the substrate in the reaction buffer before starting the reaction.

Transformation rates close to $94 \%$ of the potentially transformable substrate (linolenic and linoleic acid) were obtained for hydrolized flax seed oil concentrations of $32 \mathrm{~g} / \mathrm{l}$ and $54 \mathrm{~g} / \mathrm{l}$ using respectivelly 46 and 76 millons of lipoxygenase units/l (Figure 3). The kinetic of the reaction was followed by the Surrey method (Surrey, 1964) and was confirmed by the analysis of the final reaction products by GC in order to determine the fatty acid profile. Almost no linolenic acid (1.5\% of the initial concentration) and small amount of linoleic acid ( $25 \%$ of the initial concentration) could be detected while the palmitic and stearic acid composition was not modified. This last result reveales a higher affinity of Lox-1 for linolenic acid compared to linoleic acid.

For a concentration of hydrolyzed flax seed oil of $143 \mathrm{~g} / 1$ representing $78.5 \mathrm{~g}$ linolenic acid and $21.5 \mathrm{~g}$ linoleic acid/1 (200 millons of lipoxygenase units/1), the limit of solubility was reached. In this last case, the transformation rate was reduced to $60 \%$ meaning that $50.3 \mathrm{~g}$ of linolenic acid and $9.7 \mathrm{~g}$ of linoleic acid have been transformed per liter (total amount of fatty acid transformed: $60 \mathrm{~g} / \mathrm{l}$ ). as shown in Figure 3, the reaction is almost completed in one hour.

The hydroperoxides produced in the reactor scale productions were submitted to HPLC analysis. The final composition in hydroperoxide for the different substrate concentrations used is presented in Figure 4 revealing in all cases a majority of 13-isomers ( $>95 \%$ of the total hydroperoxide content) among which a majority of 13-hydroperoxide from linolenic acid $(>80 \%)$. 


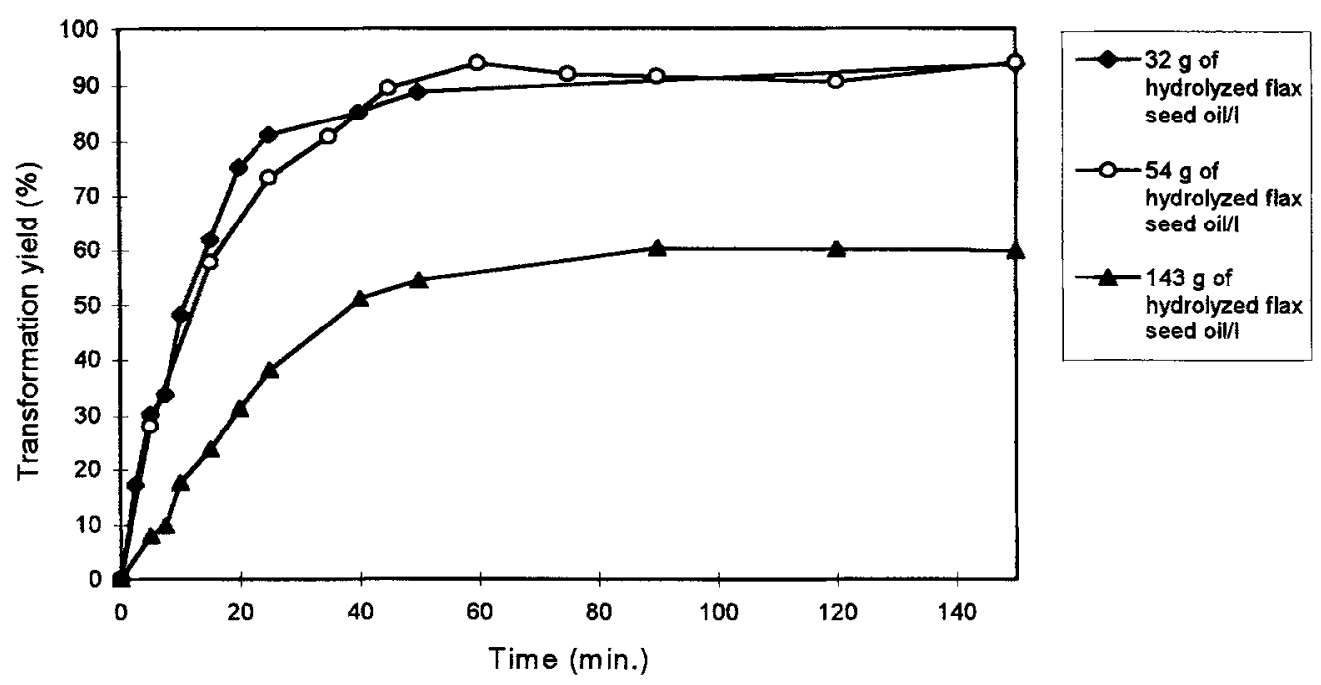

Figure 3 : Transformation yields as a function of time in 10 liters productions.

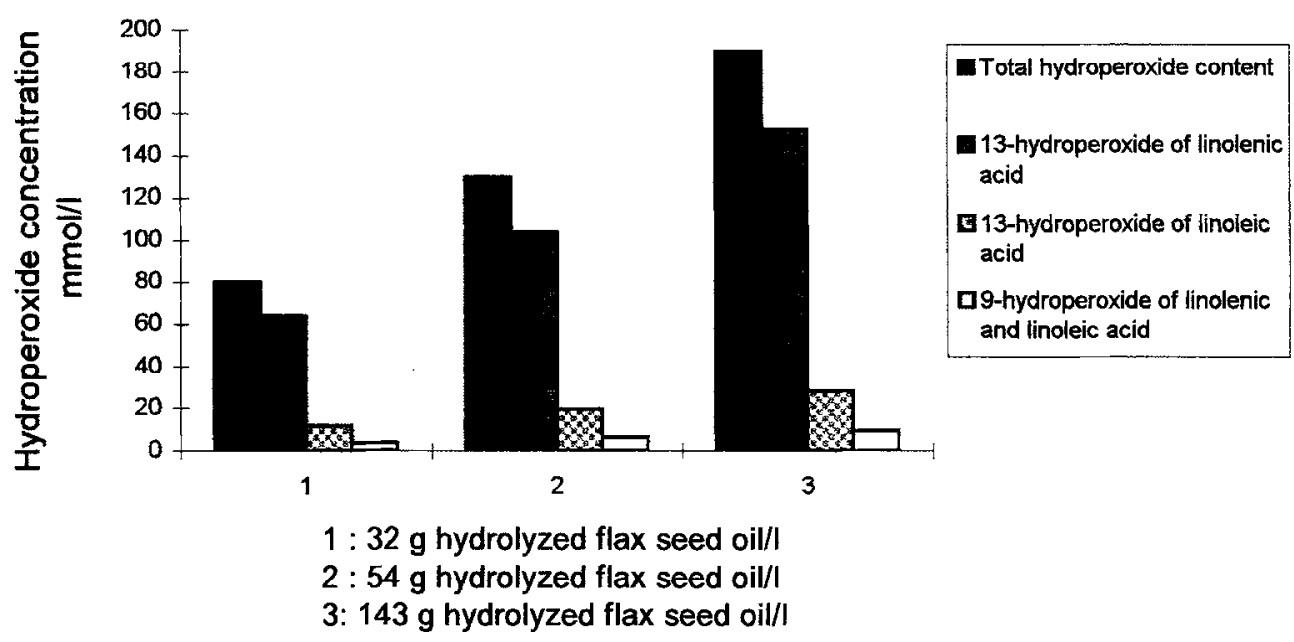

Figure 4 : Final composition in hydroperoxide for different substrate concentrations in 10 liters reactions.

Additional experiments were undertaken to understand the difference of the reaction rates obtained in laboratory scale productions and the in reactor ones. This difference could be explained by an enzyme and/or a substrate inhibition of the enzyme or by the inaccesibility of the substrate by the enzyme. We first realized a laboratory scale production using 25,000 units of lipoxygenase activity and a substrate concentration of $13 \mathrm{mmol} / \mathrm{l}$. After one hour of reaction, the maximum of transformation is reached but all the substrate is not consumed; we added at this moment 25,000 units of fresh lipoxygenase and observed that the enzyme was unable to transform the remaining substrate. In another experiment realized in the same conditions, we added fresh substrate at the same concentration as the initial one, respectivelly after 20 and 40 minutes (Figure 5).The addition of fresh linolenic acid resulted in a 'restart' of the reaction revealing that the enzyme was not inhibited at the end of the reaction by its products or substrate.The last observations allowed us to conclude that the rate limiting factor was the accessibility of the substrate for the enzyme. This consideration is in agreement with the good results obtained in reactor conditions where the agitation is better than in laboratory scale 
productions. The explanation could provide from the hydrophobicity of hydroperoxide and their tendancy to stay at the periphery of fatty acid droplets, limiting the access of the enzyme to its substrate. When the agitation is more efficient, the droplets are continually broken furnishing new reaction surfaces to the lipoxygenase.

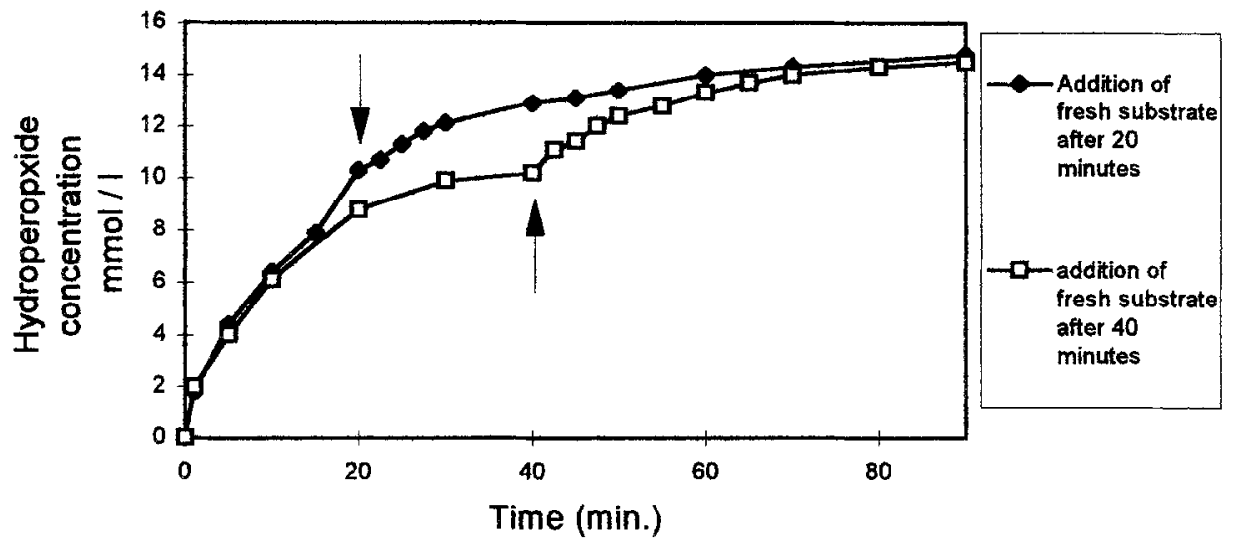

Figure 5 :Addition of fresh substrate after 20 and 40 minutes of reaction.

\section{Conclusion}

We describe herein an efficient procedure for producing 13-hydroperoxides from linolenic acid using soybean lipoxygenase. The production yields $\left(60 \mathrm{~g} .1^{-1} \cdot \mathrm{h}^{-1}\right)$ obtained in a 10 liter reactor are better than the results previously reported $\left(22 \mathrm{~g} \cdot 1^{-1} \cdot \mathrm{h}^{-1}\right)$. The procedure is also simple because it requires no solvent or surfactant and it is conducted at atmospheric pressure. it is relatively cheap as the enzyme is extracted from soybean seeds and as hydrolized flax seed oil is used as a source of linolenic acid. For fatty acid concentrations up to $54 \mathrm{~g} / \mathrm{l}$, almost all the potentially transformable substrate is oxygenated $(94 \%)$ and the purity of the final products is high ( $>95 \%$ of 13 -isomer among which $80 \%$ of 13 -hydroperoxide of linolenic acid). We have also pointed out that the rate limiting factor was the accessiblity of the substrate for the enzyme which means that the agitation conditions are critical to reach high product concentrations.

\section{References}

Axelrod, B., Cheesbrough, T.M. and Laakso, S. (1981). Methods in Enzymology 71, 441-446.

Chism, G.W. (1985). Soy lipoxygenase. in : Flavor Chemistry of Fats and Oil, D.B. Min and T.H.Smouse, eds. pp. 175-187, Champain (Illinois), USA: American Oil Chemists'Society.

Drouet, P., Thomas, D. and Legoy, M.D. (1994). Tetrahedron Letters. 35 ,3923-3926.

Fauconnier, M.-L. and Marlier, M. (1996). Grassa y Aceites, 4, July-Augustus (in press).

Hatanaka, A. (1993). Phytochemistry. 34, 1201-1218.

Hildebrand, D. (1989). Physiologia Plantarum. 76, 249-253.

Iacazio, G., Langrand, G., Baratti, J., Buono, G. and Triantaphylides, C. (1990). J. Org. Chem. 55, 1690-1691.

Leu, K. (1974). Lebensm. Wiss. Technol. 7, 98-100.Lognay, G., Marlier, M., Baudart, E., Severin, M. and Casimir, J. (1988). Riv. Sostanze Grasse. 65, 291-294.

Sanz, L.C., Perez, A.G., Rios, J.J. and Olias, J.M. (1993). J. Agric. Food Chem. 41, (5), 696-699.

Surrey, K. (1964). Plant Physiol., $39,65-70$. 